\title{
ABBREVIATED SOURCE TITLES
}

For newspapers, weeklies, and journals the country of origin is indicated in parentheses.

Biull. nauchn. inf.

$E k$.

Ek. gaz.

Ek. nauki

Ek. Pol.

Ek. sel'. khoz.

Gosp. Plan.

Itogi-1959-SSSR

Ist. arkh.

Izv. Ak. Nauk

Izv. Sib. otd.

Izv. Timir. Sel'. Ak.

Kap. stroi.-1961
Biulleten' nauchnoi informatsii: Trud $i$ zarabotnaia plata (Soviet)

Ekonomista (Polish)

Ekonomicheskaia gazeta (Soviet)

Nauchnye doklady vysshei shkoly:

Ekonomicheskie nauki (Soviet)

Ekonomska Politika (Yugoslav)

Ekonomika sel'skogo khoziaistva (Soviet)

Gospodarka Planowa (Polish)

Tsentral'noe Statisticheskoe Upravlenie pri Sovete Ministrov SSSR, Itogi vsesoiuznoi perepisy naseleniia 1959 goda. SSSR: svodnyi tom (Moscow: 1962)

Istoricheskii arkhiv (Soviet)

Izvestiia Akademii Nauk SSSR (Soviet)

Izvestiia Sibirskogo otdeleniia Akademii Nauk SSSR (Soviet)

Izvestiia Timiriazevskoi Sel'skokhoziaistvennoi Akademii (Soviet)

Tsentral'noe Statisticheskoe Upravlenie pri Sovete Ministrov SSSR, Kapital'noe stroitel'stvo v SSSR (Moscow: 1961) 
Khim. sots. zem.

Komm. Uzbek.

Kon. tsifry-1929/30

Kul't. stroi.-1956

Lit. gaz.

Na agr. fronte

Narkhoz-. . .

Narkhoz-RSFSR-. . .

Nowe Roln.

Part. zh.

Plán. hosp.

Plan. khoz.

Pochv.

Pos. ploshch.

Prob.ek.

Prom. SSSR-1964

Rocz. Stat.-. . .

Sakh. prom.

Sel'. khoz.
Khimizatsiia sotsialisticheskogo zemledeliia (Soviet)

Kommunist Uzbekistana (Soviet)

Gosplan SSSR. Kontrol'nye tsifry narodnogo khoziaistva SSSR na 1929/ 30 god (Moscow: 1930)

Tsentral'noe Statisticheskoe Upravlenie pri Sovete Ministrov SSSR, Kul'turnoe stroitel'stvo SSSR (Moscow: 1956)

Literaturnaia gazeta (Soviet)

Na agrarnom fronte (Soviet)

Abbreviation used for the official Soviet statistical handbook, published in Moscow under the title Narodnoe khoziaistvo SSSR v . . g. g., usually in the year following that referred to in the title Tsentral'noe Statisticheskoe Upravlenie pri Sovete Ministrov RSFSR, Narodnoe khoziaistvo RSFSR $v \ldots$. g. (Moscow)

Nowe Rolnictwo (Polish)

Partiinaia zhizn' (Soviet)

Plánované hospodárství (Czechoslovak)

Planovoe khoziaistvo (Soviet)

Pochvovedenie (Soviet)

Tsentral'noe Statisticheskoe Upravlenie pri Sovete Ministrov SSSR, Posevnye ploshchadi SSSR (Moscow: 1957), 2 volumes

Problemy ekonomiki (Soviet)

Tsentral'noe Statisticheskoe Upravlenie pri Sovete Ministrov SSSR, Promyshlennost' SSSR (Moscow: 1964)

Abbreviation used for the official Polish statistical handbook published in Warsaw under the title Rocznik Statystyczny ... in the year referred to in the title

Sakharnaia promyshlennost' (Soviet) Sel'skoe khoziaistvo (Soviet) 
Xxiv

Sel'khoz-1960

Sel'.zh.

Soc. Pol.

Soc. Sela

Sots. khoz.

Sots. rek. sel'. khoz.

Sots. sel'. khoz.

Sots. zem.

Sov. Ross.

Sred. spets. obraz.-1962

SSSR v tsifrakh-1964

Stat.

Stat. God.-1964

Stat. přeh.

Stat. Rev.

Stat. roč.-. . .

Stroi. komm.

Trud.Vol'. ek. obshch.

Uchet i fin.

Vest. Ak. Nauk
Abbreviated Source Titles

Tsentral'noe Statisticheskoe Upravlenie pri Sovete Ministrov SSSR. Sel'skoe khoziaistvo SSSR (Moscow: 1960)

Sel'skaia zhizn' (Soviet)

Socijalna Politika (Yugoslav)

Sociologija Sela (Yugoslav)

Sotsialisticheskoe khoziaistvo (Soviet)

Sotsialisticheskaia rekonstruktsiia sel'skogo khoziaistva (Soviet)

Sotsialisticheskoe sel'skoe khoziaistvo (Soviet)

Sotsialisticheskoe zemledelie (Soviet)

Sovetskaia Rossiia (Soviet)

Srednee spetsial'noe obrazovanie v SSSR (Moscow: 1962)

Tsentral'noe Statisticheskoe Upravlenie pri Sovete Ministrov SSSR, SSSR v tsifrakh $v 1964$ godu (Moscow: 1965)

Statistika (Czechoslovak)

Savenzi Zavod za Statistiku, Statistički

Godišnjak SFRJ, 1964 (Belgrade:

1964)

Statistické přehledy (Czechoslovak)

Statističke Revije (Yugoslav)

Abbreviation used for the official Czechoslovak statistical handbook, published in Prague until 1959 under the title Statistická ročenka Republiky Československé . . . and thereafter as Statistická ročenka Československé socialisticke republiky .... in the year referred to in the title

N. S. Khrushchev, Stroitel'stvo kommunizma i razvitie sel'skogo khoziaistva v SSSR (Moscow: 1962-1964) 8 volumes

Trudy Vol'nogo ekonomicheskogo obshchestva (Russian)

Uchet $i$ finansy $v$ kolkhozakh $i$ sovkhozakh (Soviet)

Vestnik Akademii Nauk (Soviet) 
Vest. Mosk. Un.

Vest. sel'. nauki

Vest. stat.

Vnesh. torg.-. . .

Vop.ek.

Vop. fil.

Vop.geog.

Vyssh. obraz.-1961

Wiés Wspót.

Za soc. zem.

Zag. Ek. Roln.

Zem.

Zem.ek.

Zem. nov.

Zhen. i deti-. . .

Zhen.-SSSR-1960

Życie Gosp.
Vestnik Moskovskogo Universiteta (Soviet)

Vestnik sel'skokhoziaistvennoi nauki (Soviet)

Vestnik statistiki (Soviet)

Abbreviation used for the official Soviet handbook of statistics on foreign trade, published in Moscow under the title Vneshnaia torgovlia SSSR za . . god (or gody)

Voprosy ekonomiki (Soviet)

Voprosy filozofii (Soviet)

Voprosy geografii (Soviet)

Vysshee obrazovanie $v$ SSSR (Moscow:

1961)

Wies Wspótczesna (Polish)

Za socialistické zemědělství (Czechoslovak)

Zagadnienia Ekonomiki Rolnej (Polish)

Zemledelie (Soviet)

Zemědělská ekonomika (Czechoslovak)

Zemědělské noviny (Czechoslovak)

Abbreviation used for the official handbook of statistical data on women and children published in Moscow under the title Zhenshchiny $i$ deti $v$ SSSR in 1961 and again in 1963 Zhenshchina v SSSR (Moscow: 1960) Życie Gospodarcze (Polish) 
